\title{
CONCEPTS AND TECHNIQUES OF NASAL TIP SURGERY
}

\author{
Prof. Dr. John M. Hodges M.D., F.A.C.S., Prof. Dr. Abd El-Zaher El-Sayed Tantawy M.D., Prof. Dr. Tarek Ab El- \\ Moaty Omran M.D., Prof. Dr. Atef Taha El-Bahrawy M.D., Dr Ahmed M. Anany M.D., Dr Said Abd El \\ Moneem M.D., and Ahmed Ibrahim Ali, M.D. \\ Otolaryngology Department, Medical School, Tennessee University, USA - Otolaryngology Department, Faculty \\ of Medicine, Zagazig University, Egypt.
}

\begin{abstract}
Background: Rhinoplasty is one of the most challenging procedures in plastic surgery. It is technically demanding, and tip surgery is an art form. It requires an in-depth knowledge of the complex three-dimensional anatomy of the nose, a complete understanding of its physiology, familiarity with the described techniques of nasal tip surgery, and a well-developed sense
\end{abstract} of aesthetics.

Aim of the work: This article will describe different techniques used to create a refined, aesthetically pleasing nasal tip. Patients and methods: The patients in this study were selected from of Dr John Hodges, M.D' Office, Veterans Hospital, and Methodist hospital, USA, and Zagazig University hospital, Egypt. The study was carried out on 50 patients with different nasal tip deformities, who underwent rhinoplasty, they were 15 males and 35 females, their age ranging from 20 to 60 years old. Two approaches had been selected; an open approach had been done for $30 \%$ of our patients, and a closed approach had been done for $70 \%$ of our patients with different nasal tip techniques.

Results: The results of this study for nasal tip refinement techniques demonstrated a decrease in reductive and irreversible techniques as cartilage transection, domal truncation, morselization, and scoring that had been done in $8 \%$ of our patients for each, with a concurrent increase in stabilizing, strengthening, and reorientation techniques as sutures and grafts techniques that had been done in $60 \%$ of our patients for each; so cartilage-dividing techniques and the vertical dome division are rarely necessary to reduce projection, broadness, and/or rotation of nasal tips, they have been used if suture and graft techniques do not achieve the adequate nasal tip definition.

Conclusion: The simplest approach for refinement of nasal tip deformity that allows the planned surgical techniques to be performed without difficulty and cause the least disturbance to the tip's support, should be selected. Thus, we recommend the reversible, non destructive techniques as sutures and tip grafts for remodeling the tip deformities, with closed approach once indicated.

Keywords: Rhinoplasty, nasal tip refinement

\section{INTRODUCTION}

$\mathbf{N}$ asal tip surgery is generally recognized as the most complex portion of rhinoplasty, and tip irregularities are a common cause of revision rhinoplasty ${ }^{(1)}$.

The three-dimensional structural anatomy of the nasal tip is complex; the interrelationship between these structures determines the ultimate form and function of the nasal tip. As a result, alteration of one structure in the tip will often lead to change in other portions of the nasal tip ${ }^{(2) .}$

The universal goal of nasal tip surgery is to create a stable, symmetric, and aesthetically projected and rotated nasal tip that is triangular at base view and harmonious with the rest without causing functional impairment ${ }^{(3)}$.

A plethora of techniques for nasal tip surgery have been described by scores of surgeons over the years in an effort to clarify their concepts and promote the validity of their maneuvers. The resultant collage of techniques can confuse even the most experienced rhinoplasty surgeon. However, one concept that has stood the test of time is the tripod concept of nasal tip dynamics, as first proposed by Anderson ${ }^{(4)}$. His important yet simple concept has aided thousands of rhinoplasty surgeons in understanding nasal tip dynamics and achieving improved results. It defines the conjoined medial crura as one leg of a tripod and each of the lateral crura as the other legs. The lengths of these legs can be altered to change the position of the tip ${ }^{(5)}$.

In the past 20 years, a striking revolution has occurred in the fine points of analysis and technique, guided by surgeons devoted to tissue reorientation and augmentation rather than resection, individualization of technique rather than a lock-step approach, and atraumatic tissue dissection in proper nasal cleavage planes. Shaping the nasal tip by scoring, morselization, resection, or transection of the alar cartilages (destructive techniques) disrupts the structural integrity of the alar archs sacrificing support and introducing variables surgeons cannot control. When alternative non destructive techniques as sutures are available and equally effective, a decision to use destructive technique is a flawed decision because it introduces additional uncontrolled variables that increase risks of secondary deformities ${ }^{(6) .}$

Over the decades, suture techniques were introduced intermittently, but to a limited extent. It was not until the early 80s that there was a surge in suture techniques to control tip shape. Tardy et al ${ }^{(7)}$ 
introduced one of the first techniques, a suture to reduce the width of the domes in the closed approach. Daniel ${ }^{(8)}$ popularized a dome control suture for the open approach. J. Tebbetts ${ }^{(9)}$ more than anyone else at the time, suggested a change in our approach to cartilage control by suggesting non destructive techniques. A number of suture techniques to control virtually every part of the nasal tip complex became available (10). Because suture techniques are intended to change the shape of tip cartilages, the assumption is that there is cartilage of sufficient size and integrity to permit the application of suture techniques. When cartilage is missing or extraordinarily weak, grafting is necessary. Tip grafts, columellar struts, spreader grafts, and lateral crural struts will not lose their significant roles in rhinoplasty simply because suture techniques are available ${ }^{(11)}$.

Every surgical operation has a tendency to complications, and only the surgeon who does not operate has no complications. Knowledge of relevant complications and sequelae is essential to enlighten the patient so that an informed decision can be made, for reducing the incidence of such complications, and for treating a complication once it has occurred.

\section{PATIENTS AND METHODS}

This study was carried on 50 patients and selected from of Dr John Hodges, M.D' Office, Veterans Hospital, Methodist hospital, USA, and Zagazig University Hospitals, Egypt. The age of the patient ranged from 18 to 50 years old, with mean age for male 27.13years, and mean age for females 33.56 years.

The entire patients were subjected to full history taking, external and internal nasal examination, computer tomography is used in some selected patients, for evaluation the nasal cavity and to detect any associated pathology as sinusitis or nasal mass, and preoperative and postoperative photographs taking in 5 standard views; frontal, lateral, oblique, base, and high Skye views. This series of pictures is fundamental and should be taken for all patients. All the basic views presented in this study are taken at a fixed subject-camera distance of $1.5 \mathrm{~m}$ with a digital SLR camera (Canon T1i). Care should be taken to maintain the camera at the same height as the subject.

There were aesthetic indications for rhinoplasty only for 28 patients (56\%), 22 patients (44\%) with combined (aesthetic and functional) indications, and no patient had functional indication only.
The patients in this study had different nasal tip deformities; the majority of our patients $(40 \%)$ had bulbous nasal tip, $30 \%$ of patients with asymmetric nasal tip, $28 \%$ over-projected nasal tip, underrotated nasal tip, broad, and under-projected nasal tip 14\% of patients for each, boxy, and over-rotated nasal tip $10 \%$ of patients for each, smiling, platyrrhine, cleft, and pinched nasal tip $4 \%$ of patients for each, and $2 \%$ of patients had ball nasal tip (figures1- 13 show different nasal tip deformities in our study). The most of patients had more than one nasal tip deformity.

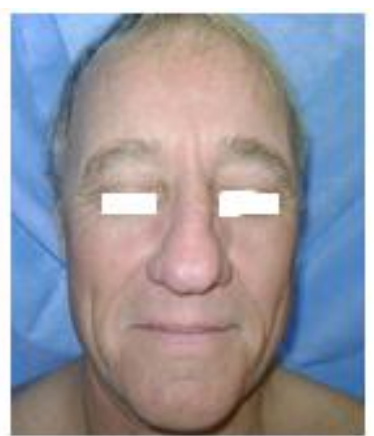

Fig. 1 Bulbous nasal tip

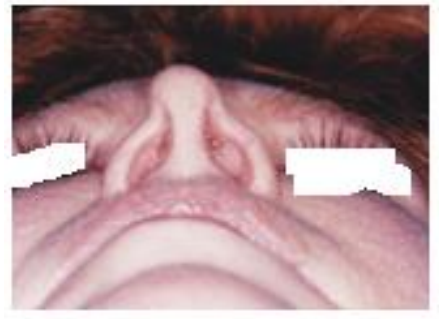

Fig. 2 Pinched Nasal Tip Fig.

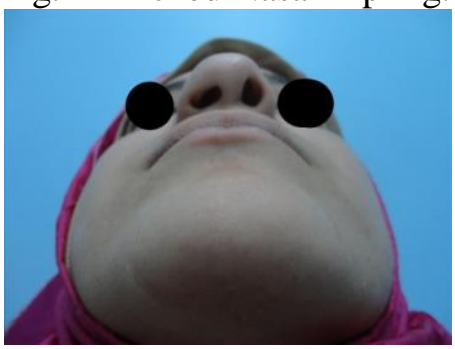

Fig. 3 Unilateral cleft nose

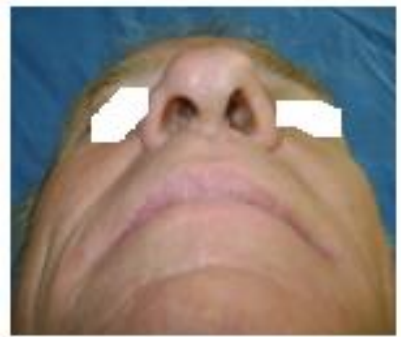

Fig. 4 Nasal tip asymmetry 


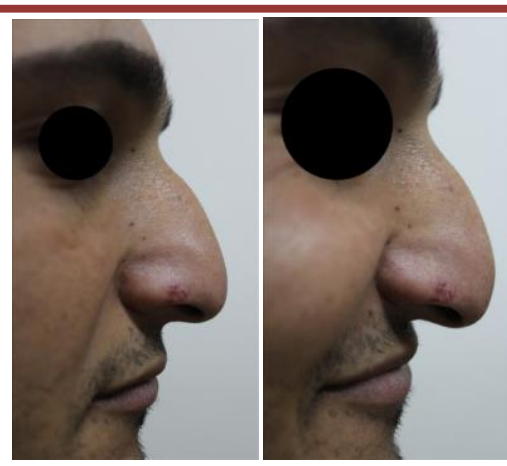

Fig. 5 Smiling deformity

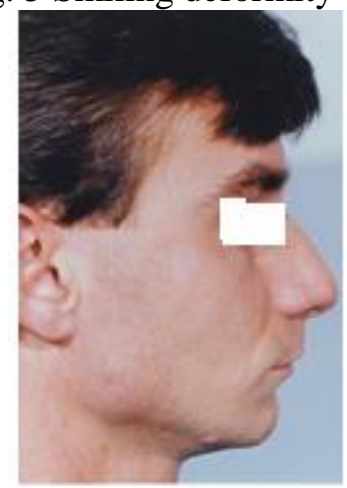

Fig. 6 Platyrrhine Nose

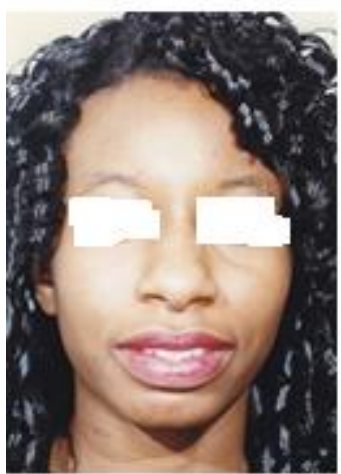

Fig. 7 Broad nasal tip

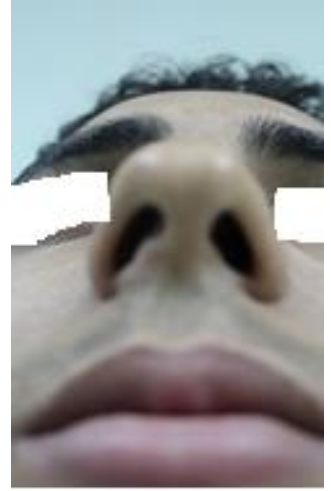

Fig. 8 Boxy nasal tip

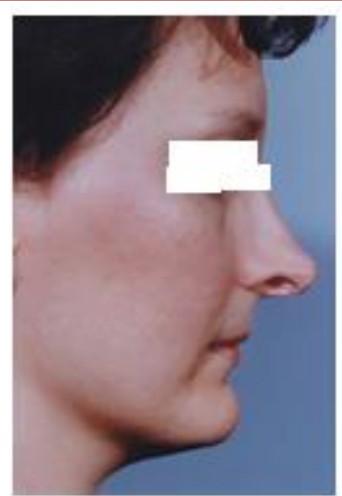

Fig.9 Overprojected nasal tip

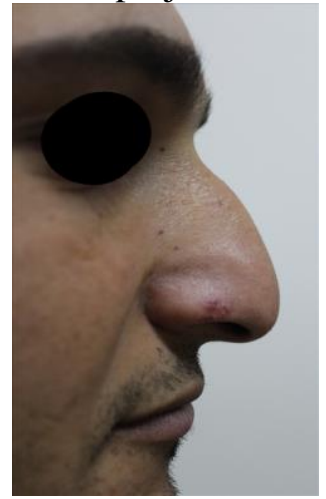

Fig. 10 Tension nose

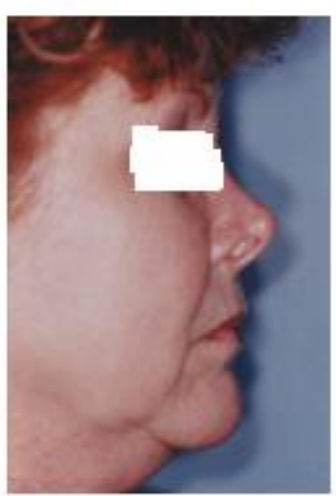

Fig. 11 Short nose

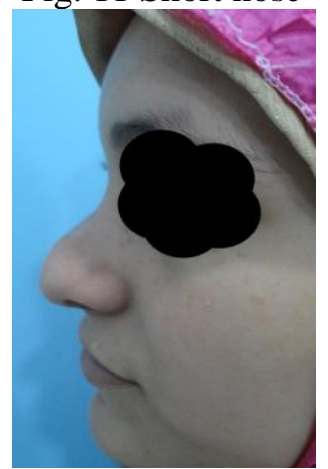

Fig. 12 Underprojected nasal tip 


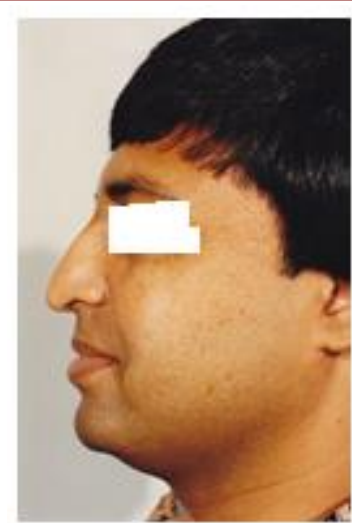

Fig. 13 Droopy nasal tip

The Majority of patients $(70 \%)$ had been operated under Local anesthesia, while only $15 \%$ of patients had been operated under general anesthesia. We preferred to perform endonasal rhinoplasty exclusively under local anesthesia with intravenous analgesia. We used general anesthesia only under special circumstances, such as in a remarkably anxious patient, patient who does not speak the same language and therefore cannot respond to any reassuring or instructive dialog during the procedure, a patient with severe attention deficit hyperactivity disorder, or, occasionally, for live surgical demonstration. Local anesthesia has the advantages of safety and helps the surgeon to operate in bloodless field.

\section{-Approaches for nasal tip surgery:}

There are two schools of approach in modern rhinoplasty - the open approach and the closed approach. Although both approaches have their advantages and disadvantages, it is important to be familiar with both. The experienced surgeon tailors the approach to the patient's anatomic deformity. Regardless of the approach, however, the modifications made to the underlying framework ultimately supersede the choice of incision type used.

\section{1- Closed (endonasal) approach:}

The non-delivery approach is an endonasal approach very suitable for achieving minor modifications of the nasal tip such as a moderate increase in tip rotation or an improvement in tip definition. The non-delivery approach is particularly suitable for patients with reasonable tip symmetry, normal domal angles, and normal interdomal distances (figure 14), as this approach does not allow any modification of the domal angles or a narrowing of the interdomal distance. In this study, $30 \%$ of our patients had been underwent non delivery approach of lower lateral cartilage for nasal tip refinement (figure 15).
The delivery approach is another endonasal approach allowing modification of nasal tip by remodeling the alar cartilages, besides providing access to the upper two thirds of the nose. We used this approach in $40 \%$ of our patients with asymmetry of nasal tip, broad nasal tip, underrotated nasal tip, under and over-projected nasal tip. With this delivery approach, excision of cartilage is possible under direct visual control of the alar cartilages, it is possible to introduce and fixate cartilaginous grafts, and it is also possible to interrupt the continuity of the alar cartilages to change nasal projection, broadness, and rotation.

There are many surgical procedures to deliver the alar cartilages:

1-An intercartilagenous -marginal incisions, that been described in many studies (figure 16)

2- Transcartilagenous -marginal incisions; this precludes the potential danger of postoperative scarring at the internal nasal valve.

3-Marginal incision only; Delivery of alar cartilags can be done through marginal incision only, but it needs high experienced nasal surgeons to modify the alar cartilage without distortion and maintain the vestibular skin intact without tear. This also precludes the potential danger of postoperative scarring at the internal nasal valve (figure 17).

\section{2- Open approach:}

We recommended this approach in our study for $30 \%$ of patients had nasal tip deformities associated with tension nose, gross nasal dorsum deformity, nasal valve narrowing, and cleft tip nose. The advantages of the open approach are greater control of the surgery and bleeding, and accurate ease of optimal graft placement and suturing. The disadvantages are a longer operation time, risk of tip edema, trans-columellar scarring, and difficultly in creating pockets for graft stabilization (figure 18).

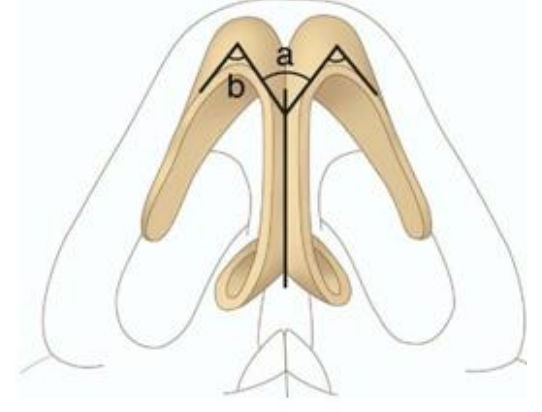

Fig.14 The dome of nasal tip (A) Angle of domal divergence (B) Angle of domal definition ${ }^{(12) .}$ 


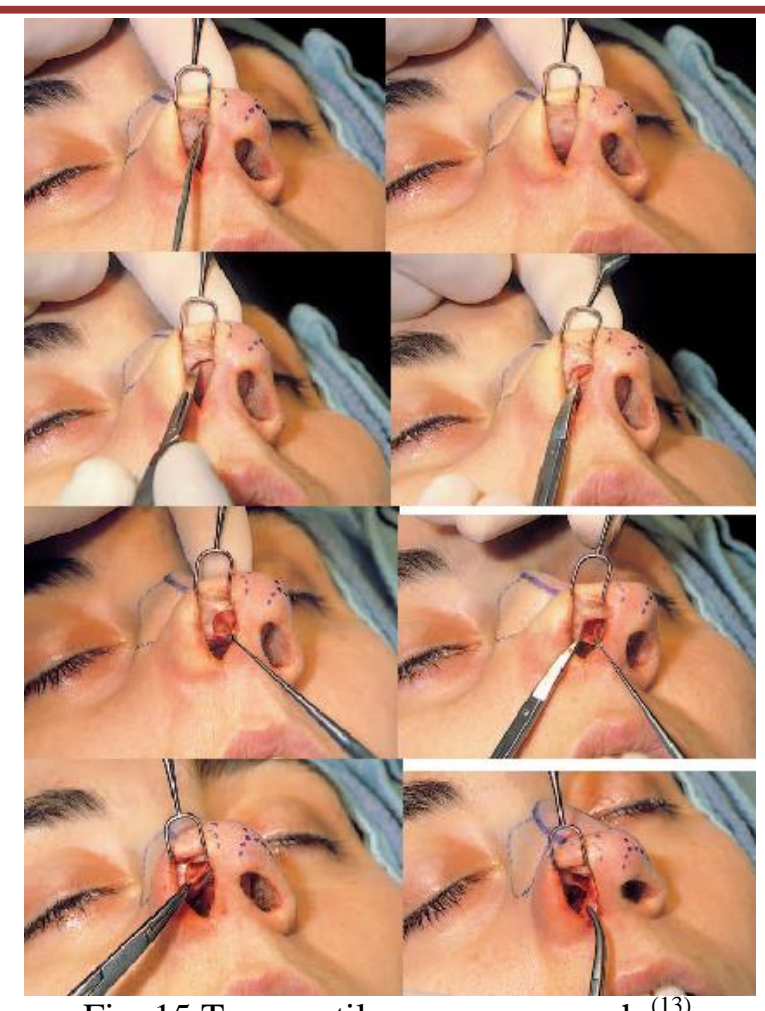

Fig. 15 Transcartilagenous approach
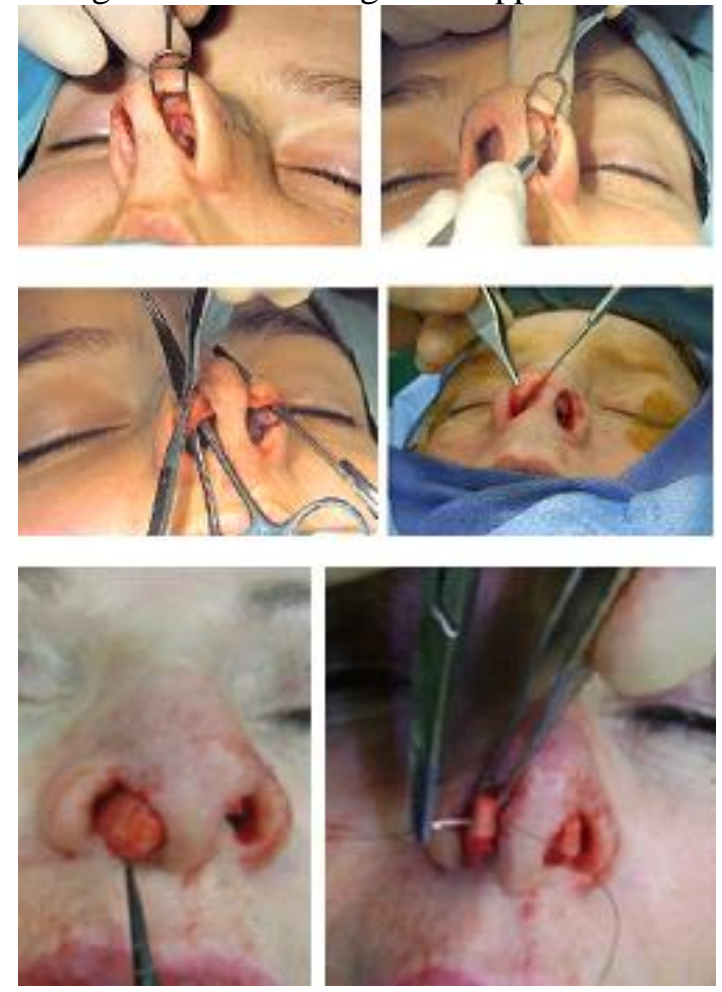

Fig. 16 Delivery approach through an intercartilagenous and marginal incision

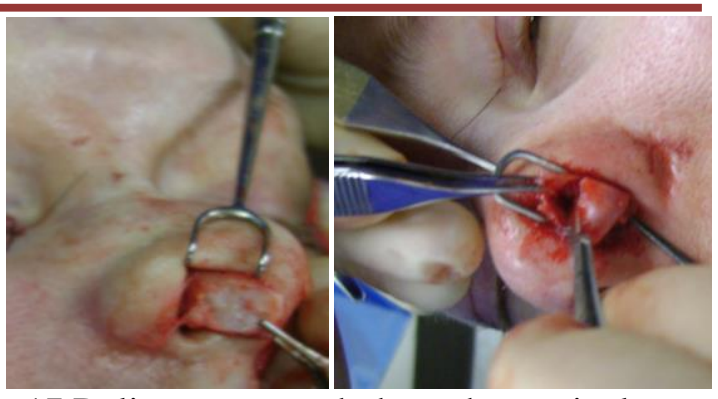

Fig. 17 Delivery approach through marginal incision
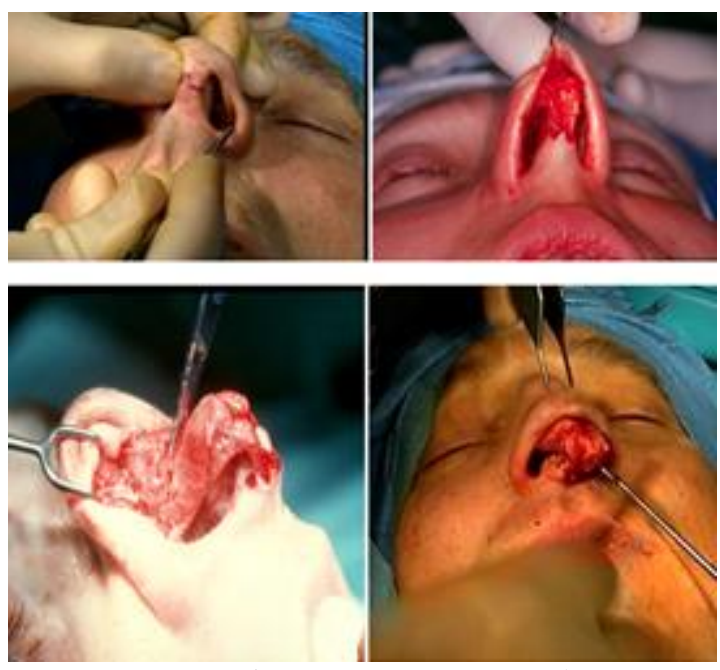

Fig. 18 Open approach

\section{-Techniques for nasal tip modifications:}

Reversible and nondestructive with tissue augmentation and reorientation techniques (sutures, or grafts) should always precede more destructive techniques that are irreversible or introduce more uncontrollable variables (scoring, morselization, or transaction of cartilage). Destructive techniques interrupt the structural integrity of the alar crura, weakening the cartilages, decreasing tip support, and making the cartilages more subject to distortion by postoperative wound contraction forces. Nevertheless, destructive techniques have a place in primary rhinoplasty, but a place that is rapidly changing to more predictable and precise non destructive techniques, as the surgeons will be more familiar with non destructive techniques.

The nasal tip contouring maneuvers that have been evaluated in this study were classified as either reductive or stabilizing and strengthening and are summarized in the (Table 1).

In our study, inter-domal sutures had been done for $60 \%$ of patients, columellar-septal sutures had been done for $38 \%$ of patients, medial crural fixation sutures had been done for $34 \%$ and transdomal sutures had been done for $20 \%$ for our 
patients (figure 19). (Table 2)

Coulmellar strut had been done in our study for $60 \%$ of patients, only tip graft $14 \%$, plumping and caudal extension grafts had been done for $10 \%$ each, shield graft $8 \%$, alar batten graft $4 \%$, and finally; alar strut graft had been done for $20 \%$ of our patients (figure 20). (Table 3)

In our study, $68 \%$ of the patients underwent resection of the cephalic part of LLC (A conservative cephalic trim should preserve at least 8 to $10 \mathrm{~mm}$ laterally and 5 to $7 \mathrm{~mm}$ medially of alar cartilage), $16 \%$ underwent morselization (figure 21) and vertical dome division for each (figure 22). (Table 4)
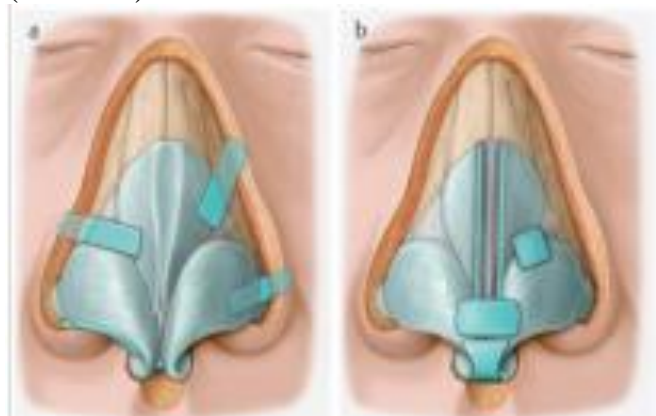

Fig. 20 Structural grafts. a) From top to bottom: Vertical alar batten graft, horizontal alar batten graft, alar strut graft, alar rim graft, columellar strut graft. b) From top to bottom: Paired spreader grafts, cap graft, shield-type tip graft. ${ }^{(23)}$
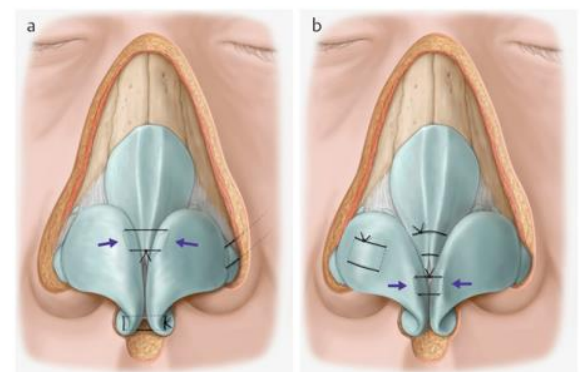

Fig. 19 Frequently placed sutures. a) From top to bottom: High interdomal suture, flaring suture and middle crural suture. b) From top to bottom: Flaring suture, lateral crura suture, interdomal suture. ${ }^{(23)}$

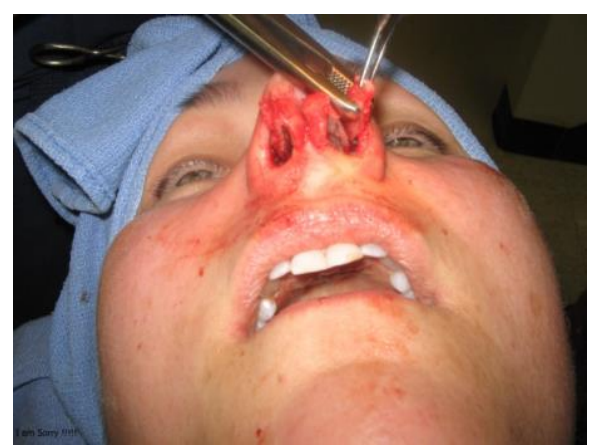

Fig.21 Morselization

Table 1: Classification of nasal tip contouring maneuvers

\begin{tabular}{|c|c|}
\hline $\begin{array}{l}\text { Stablilizing and } \\
\text { strengthening }\end{array}$ & Reductive \\
\hline $\begin{array}{l}\text {-Interdomal suture } \\
\text { - Intradomal suture } \\
\text {-Medial crural fixation } \\
\text { sutures } \\
\text { - Flare control sutures } \\
\text { - Lateral crural spanning } \\
\text { sutures } \\
\text { - Columellar-Septal } \\
\text { sutures } \\
\text {-Suture Lift of the Nasal } \\
\text { Tip } \\
\text {-Dorsal rotation suture of } \\
\text { the nasal tip }\end{array}$ & $\begin{array}{l}\text { Excisional } \\
\text { techniques } \\
\text { 1-Cartilage } \\
\text {-Cephalic trim } \\
\text {-Medial crural } \\
\text { excision } \\
\text { - Lateral crural } \\
\text { excision } \\
\text {-Caudal septal shave } \\
\text { 2-Soft tissue } \\
\text { - Alar base } \\
\text { reduction } \\
\text {-Membranous septal } \\
\text { excision }\end{array}$ \\
\hline $\begin{array}{l}\text { Grafting techniques } \\
\text {-Structural } \\
\text { Lower lateral crural strut } \\
\text { Columellar strut graft } \\
\text { Extended collumelar strut } \\
\text { Lower lateral crural } \\
\text { batten graft } \\
\text { Caudal extension graft } \\
\text { Alar batten onlay graft } \\
\text { Alar strut graft }\end{array}$ & $\begin{array}{l}\text { Weakening } \\
\text { techniques } \\
\text { Scoring } \\
\text { Morselization }\end{array}$ \\
\hline $\begin{array}{l}\text {-Contour } \\
\text { ShieldTip grafts } \\
\text { Tip only graft } \\
\text { Alar rim graft } \\
\text { Alar batten onlay graft }\end{array}$ & \\
\hline
\end{tabular}

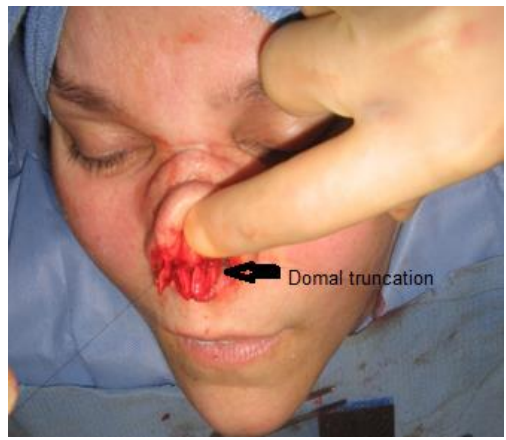

Fig. 22 Domal truncation 


\begin{tabular}{lllll}
\hline Types of & Inter- & Columellar & Medial & Trans- \\
sutures & domal & - septal & crural & domal \\
& sutures & sutures & fixation & sutures \\
& & & sutures &
\end{tabular}

\begin{tabular}{ccccc}
\hline $\begin{array}{l}\text { Number of } \\
\text { patients }\end{array}$ & 30 & 19 & 17 & 10 \\
\hline $\begin{array}{c}\% \text { from the } \\
\text { total number }\end{array}$ & $60 \%$ & $38 \%$ & $34 \%$ & $20 \%$ \\
\hline
\end{tabular}

Table 2: Shows numbers and percentages of different types of sutures techniques for nasal tip modifications in relation to the total numbers of patients.

\begin{tabular}{lcc}
\hline $\begin{array}{l}\text { Types of } \\
\text { grafts }\end{array}$ & $\begin{array}{c}\text { Number } \\
\text { of } \\
\text { patients }\end{array}$ & $\begin{array}{c}\text { \% from the total } \\
\text { number }\end{array}$ \\
\hline Columellar & 30 & $60 \%$ \\
strut & & $14 \%$ \\
$\begin{array}{l}\text { Only tip graft } \\
\text { Plumping graft }\end{array}$ & 5 & $10 \%$ \\
Caudal & 5 & $10 \%$ \\
extension & 5 & $8 \%$ \\
Shield graft & & $4 \%$ \\
Alar batten & 4 & $2 \%$ \\
Alar strut graft & 2 & \\
\hline
\end{tabular}

Table 3: Shows numbers and percentages of patients underwent tip modifications by using grafts technique in relation to the total number of patients.

\begin{tabular}{lcc}
\hline $\begin{array}{l}\text { Types of } \\
\text { irreversible } \\
\text { techniques }\end{array}$ & $\begin{array}{c}\text { Number of } \\
\text { patients }\end{array}$ & $\begin{array}{c}\% \text { from the } \\
\text { total number }\end{array}$ \\
\hline $\begin{array}{l}\text {-Resection of } \\
\text { cephalic part of } \\
\text { lateral crura } \\
\text {-Morselization } \\
\text { and scoring of }\end{array}$ & 34 & $68 \%$ \\
$\begin{array}{l}\text { lower lateral } \\
\text { cartilage } \\
\text {-Vertical dome } \\
\text { division and } \\
\text { cartilage } \\
\text { transaction }\end{array}$ & 8 & $16 \%$ \\
\hline Table & & \\
\hline
\end{tabular}

Table (4): Shows numbers and percentages of patients underwent irreversible techniques in relation to the total number of patients.

\section{RESULTS}

We have been used the techniques described in the "Methods" section for refinement of different nasal tip deformities. These techniques have been used on 50 patients with excellent long term results.

In this study, we did not compare the results of those different techniques, but we just described the best technique for refinement of nasal tip deformity with best results in long-term follow up from our experience.

The results of this study for nasal tip refinement techniques demonstrated a decrease in reductive and irreversible techniques as domal truncation, and morselization, which had been done in $16 \%$ of our patients for each, with a concurrent increase in stabilizing and strengthening techniques as sutures and grafts techniques that had been done in $60 \%$ of our patients for each. Because of the frequent goal of rhinoplasty is achieving an improvement in tip definition. For this purpose it is often advisable to trim the cephalic margin of the lateral crura of the alar cartilages. In our study; $68 \%$ of the patients underwent resection of the cephalic part of LLC, sometimes combining this procedure with other techniques such as inter-domal sutures that had been done for $60 \%$ of our patients.

All the noses have maintained normal function. With an average follow-up of 1.5 years, we had only one patient had platyrrhine, and another had graft displacement. None of other patients had any of other late postoperative complications that may occur following rhinoplasty which

are, failure to achieve functional goals, suture protrusion, septal perforation, persistent anesthesia, persistent anosmia, and sever psychic reactions. Patient and surgeon satisfaction, there were five aspects analyzed about patient-satisfaction; nasal tip symmetry, nostril symmetry, tip projection, tip definition, and appearance of the nasal tip only. The Majority of patients (76\%) were very satisfied, $20 \%$ of patients were satisfied, and only $4 \%$ of patients were not satisfied.

\section{DISCUSSION}

The techniques of nasal tip surgery have received a great deal of attention in the last several years.

In assessing the need for tip remodeling, the surgeon must determine whether the tip requires (1) a reduction in the volume of the alar cartilages; (2) a change in the orientation of the alar cartilages; (3) a change in the projection of the tip; (4) a cephalic rotation with a consequent increase in the nasolabial angle; (5) a narrowing of the domal angles; (6) a narrowing of the inter-domal distance. Once these factors are accurately assessed, the most favorable incisions, the approach, and the tiprefinement technique can be chosen. 
In our study, marginal incisions had been done for $70 \%$ of patients, inter-cartilagenous incisions had been done for $30 \%$, trans-fixation incisions had been done for $20 \%$, and trans-cartilagenous incisions had been done for $10 \%$ of patients.

P. Solomon et al reported 72 patients $(100 \%)$ with transfixion incision alone for assessment of the effect of transfixation incision on nasal tip deprojection, because a full transfixion incision disrupts the attachment of the medial crura to the caudal septum, which weakens nasal tip support, resulting in deprojection of the tip ${ }^{(14) .}$

The inter-cartilaginous incision necessary for the delivery approach may cause scarring at the nasal valve area and lead to postoperative functional obstruction of the nose, to prevent this potential danger; Rui Xavier et al ${ }^{(15)}$ modified the delivery approach by using a transcartilaginous incision instead of the traditional intercartilaginous incision. This precludes the potential danger of postoperative scarring at the internal nasal valve. In our study, $4 \%$ of patients operated by the same approach with patients satisfaction. This modification of the delivery approach had been described in other studies for Xavier $\mathbf{R}^{(16)}$ and Xavier $\mathbf{R}^{(17) \text {. }}$

We reported another modification for the delivery approach through only marginal incision for delivery of the lower lateral cartilage. In our study $12 \%$ of patients with nasal tip deformity without any another nasal dorsum deformity had been operated by this modifications for improvement of nasal tip definition and rotation, so no danger in the area of internal nasal valve with patients satisfaction. We recommend no sutures for closing the inter-cartilagenous incision to minimize also the risk of scar in the area of internal nasal valve.

In our study, inter-domal sutures had been done for $60 \%$ of patients, columellar-septal sutures had been done for $38 \%$ of patients, medial crural fixation sutures had been done for $34 \%$, and transdomal sutures had been done for $20 \%$ of patients.

Different nasal tip deformities reported in our study; the majority $(68 \%)$ of patients had over projected nasal tip and bulbous nasal tip; suturing techniques had been done for corrections but inadequate for nasal tip definition in some patients so aggressive techniques such as dome division and cartilage transection had been used in $16 \%$ of patients, this is also reported in the studies of Toriumi $^{(18)}$, and Athanasios et al ${ }^{(19) .}$

The suturing of the two medial crura usually provides adequate support to the tip. Goldman IB
${ }^{(20)}$ described this method as a novel technique for the improvement and stabilization of the tip without the use of grafts, but this newly formed central flap provides inadequate support, especially in cases of thick skin and weak cartilages, so in our study a columellar strut ( $60 \%$ of our patients) was placed between the two medial crura, this strut is usually cartilaginous, and harvested from the septum.

In our study, only tip graft $14 \%$, plumping and caudal extension grafts had been done for $10 \%$ each, shield graft $8 \%$, alar batten graft $4 \%$, and finally; alar strut graft had been done for only $2 \%$ of patients.

A frequent goal of rhinoplasty is achieving an improvement in tip definition. For this purpose it is often advisable to trim the cephalic margin of the lateral crura of the alar cartilages. In our study; $68 \%$ of the patients underwent resection of the cephalic part of LLC, sometimes combining this procedure with other techniques such as inter-domal sutures that had been done for $60 \%$ of our patients. In the study of Tardy ME ${ }^{(21)}$ and Nolst-Trenite' GJ ${ }^{(22) ;}$ the delivery approach, though very appropriate for accomplishing these modifications to the nasal tip and this agree with our study in $24 \%$ of patients with that previous nasal tip deformity associated with nasal dorsum deformities, and had been operated by the same approach.

In our study, $16 \%$ underwent morselization and scoring of lower lateral cartilage and $16 \%$ of patients underwent vertical dome division for deprojection of nasal tip.

In our study, about late postoperative complication, there was one patient $(2 \%)$ had have platyrrhine nasal tip, and another one (2\%) had have graft displacement, but none of the patients had failure to achieve functional goal, suture protrusion, septal perforation, persistant anesthesia, persistant anosmia, or sever psychotic reaction . No twisted tips occurred in our series similar to the study of Athanasios et al ${ }^{(19)}$ for the following reasons (1). We sutured the medial crura on the correct place; (2) it is of paramount importance that the septoplasty has been performed and the septum is straight before the nasal tip technique is carried out. If not, the septum itself can twist the tip; (3) the lateral crura must be of equal height to avoid twisting of the tip toward the shorter lateral crura. 

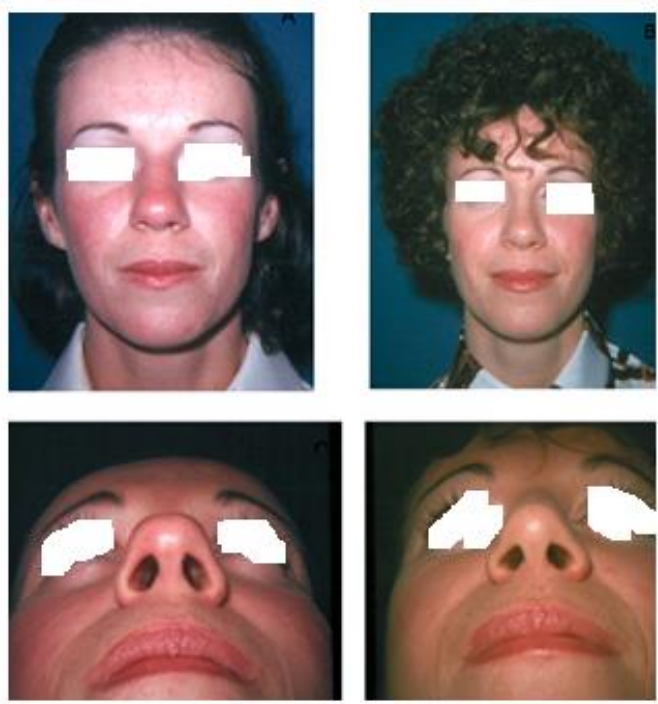

Fig. 24 A: Preoperative frontal view, Bulbous nasal tip, B: Postoperative frontal view, correction of the deformity through delivery approach, C:Preoperative basal view, D: Postoperative profile view, correction of the deformity.

Fig. 25 A: Preoperative basal view, bulbous and asymmetric nasal tip. B: Postoperative basal view, correction of the deformity, through open approach. C: Preoperative oblique view, overprojected and bulbous nasal tip. D: Postoperative oblique view, correction of the deformity.
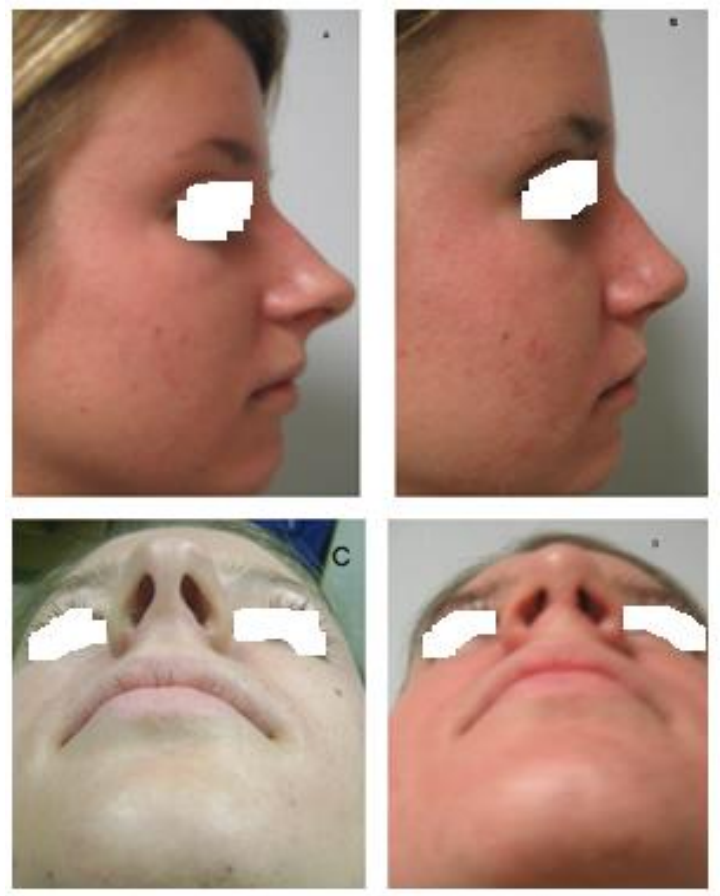

Fig. 26 A: Preoperative profile view, overprojected nasal tip. B: Postoperative profile view, correction of the deformity, through open approach. C: Preoperative basal view, boxy nasal tip. D:
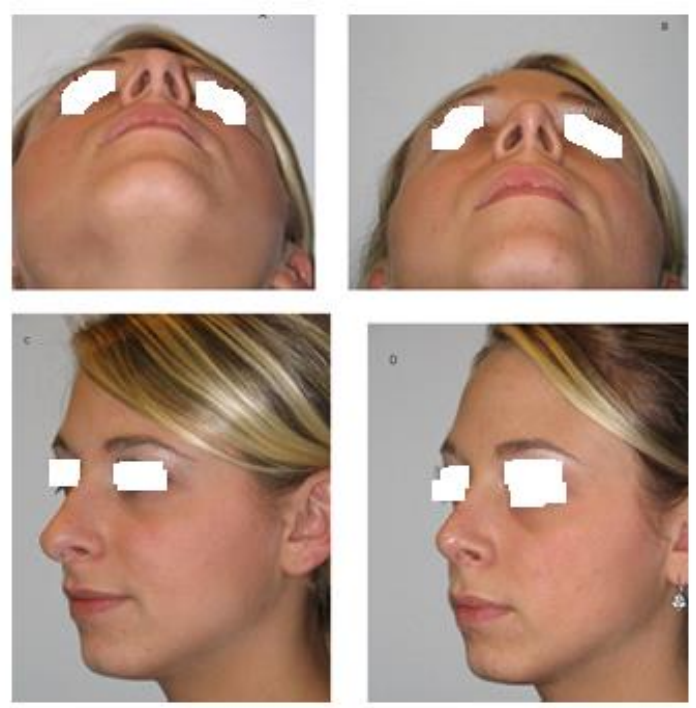

Postoperative basal view, correction of the deformity.
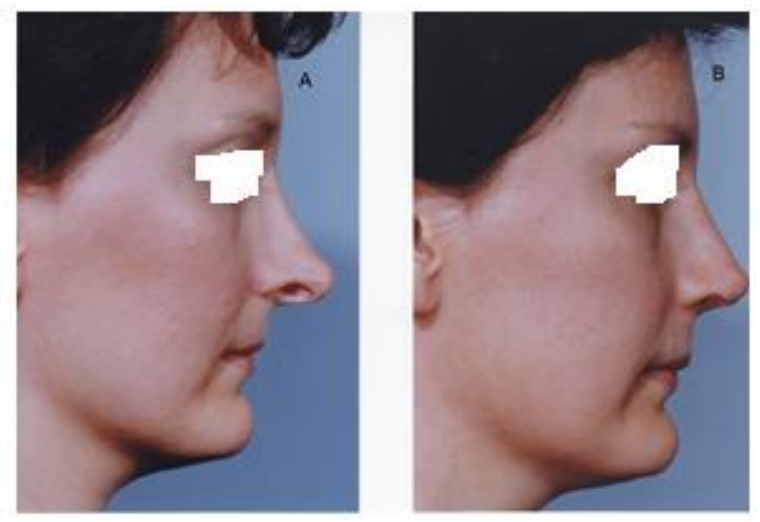

Fig. 27 A: Preoperative basal view, overprojected,andball nasal tip B: Postoperative basal view, correction of the deformity.
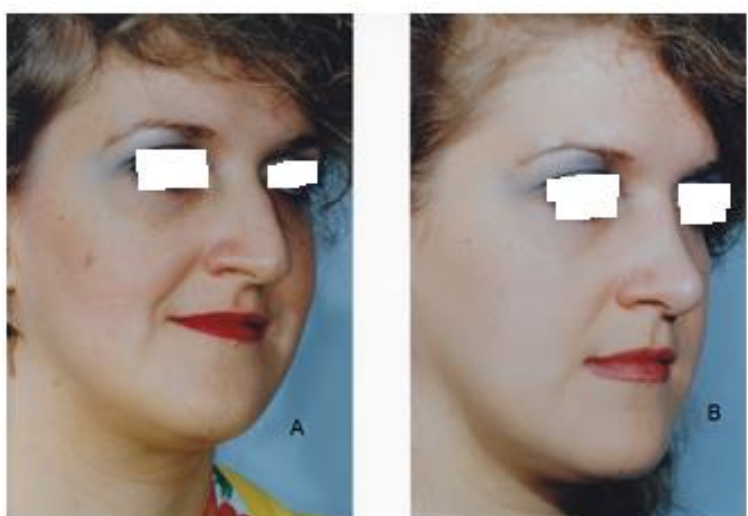

Fig. 28 A: Preoperative oblique view, tension nose $\mathrm{B}$ : Postoperative oblique view, correction of the deformity.

\section{CONCLUSION}

When selecting the approach to be used on any given patient undergo rhinoplasty, the surgeon must 
weigh the surgical trauma caused by the approach against the surgical exposure afforded by the approach. The simplest approach that allows the planned surgical techniques to be performed without difficulty and cause the least disturbance to the tip's support should be selected. Thus, the approach should be as invasive as necessary, but, at the same time, as noninvasive as possible.

Approach to nasal tip surgery for minor deformity, i.e., slight bulbosity, minimal need for rotation is the non delivery approach and the recommended incision is trans-cartilaginous or inter-cartilaginous incision.

Approach to nasal tip Surgery for moderate deformity, i.e., bulbosity, more need for rotation is the delivery approach and the recommended incisions are inter-cartilaginous with marginal incisions, trans-cartilaginous with marginal, or marginal incision only. These modifications for delivery approach tried to decrease the danger of the inter-cartilaginous incision that may cause scarring at the nasal valve area and the scroll area, and lead to postoperative functional obstruction of the nose.

Approach to nasal tip surgery for moderate or major deformity, i.e., excess bulbosity, minimal need for rotation, asymmetry, over-projection, congenital anomaly, and revision surgery is the open approach and the recommended incisions are transcolumellar with marginal incisions.

We recommend stabilizing and strengthening techniques with cartilage reorientation by sutures and grafts than reductive and irreversible techniques as cartilage transection, or resection, domal truncation, and morselization for nasal tip surgery, but we advice to trim the cephalic margin of the lateral crura of the alar cartilages because a frequent goal of rhinoplasty is achieving an improvement in tip definition when indicated.

\section{REFERENCES}

1-Oren Friedman, MD; Timur Akcam, MD; Ted Cook, MD: Reconstructive Rhinoplasty The 3 -Dimensional Nasal Tip. Arch Facial Plast Surg. 2006; 8:195-201.

2-Amy S. Ketcham, M.D. 1 Eric J. Dobratz, M.D. Normal and Variant Anatomy of the Nasal Tip. Facial Plast Surg 2012; 28:137-144.

3-Neeta Patel: Rhinoplasty.The Diffcult Nasal Tip: Total Resection of the Alar Cartilages. Aesth Plast Surg, 2009; 33: 81-83.

4-Anderson JR: The dynamics of rhinoplasty. In: Bustamant GA, ed.Proceedings of the Ninth International Congress of Otorhinolaryngology, Mexico City, August10-14, 1969. Amsterdam, the Netherlands: Excerpta Medica; 1970.

5-Peter A. Adamson, MD, FRCSC; Jason A. Litner, MD; Ravi Dahiya, MD: The M-Arch Model. A New Concept of Nasal Tip Dynamics. Arch Facial Plast Surg. 2006; $8: 16-25$.

6-John B. Tebbetts, MD (2007): Primary RhinoplastyRedefining The Logic And Techniques, 2nd edition.

7-Tardy ME Jr, Patt BS, Walter MA: Transdomal suture refinement of the nasal tip: long-term outcomes. Facial Plast Surg 1993; 9: 275-284.

8-Daniel RK, Regnault P, eds. Aesthetic Plastic Surgery. Boston: Little, Brown, 1993, 253-255.

9-John B. Tebbetts, MD: Shaping and positioning the nasal tip without structural disruption: a new, systematic approach. Plast Reconstr Surg, 1994; 94: 61-77.

10--Baker SR. Suture contouring of the nasal tip: Arch Facial Plast Surg, 2000; 2:34-42.

11-Ronald P. Gruber, MD; Jennifer Weintraub, MD; Jason Pomerantz, MD: Suture Techniques for the Nasal Tip. Aesthetic Surg J, 2008; 28: 92-100.

12-Joseph L. Leach, MD, and Raghu S. Athré, MD: Four suture tip rhinoplasty: A powerful tool for controlling tip dynamics. Otolaryngology-Head and Neck Surgery 2006; 135, 227-23.

13-J. Nolest Trenite: A practical guide to functional and aesthetic surgery of the Nose, 3rd edition, 2005.

14-P Solomon, R Rival, A Mabini, J Boyd. Transfixion incision as an initial technique in nasal tip deprojection. Can J Plast Surg 2008; 16 (4):224-227.

15-Tardy ME: Contemporary rhinoplasty: principles and philosophy. In: Behrbohm H, Tardy ME (eds) Essentials of septorhinoplasty. Thieme, Stuttgart, 2004; pp 37-63

16-Xavier R: Tip rhinoplasty - a modified delivery approach. Rhinology, 2009; 47:132-135

17- Xavier R: A modified delivery approach. In: Shiffman MA, Di Giuseppe A (eds) Advanced aesthetic rhinoplasty: art, science, and new clinical techniques. Springer, Berlin, 2013

18-Toriumi DM, Tardy ME. Cartilage suturing techniques for correction of nasal tip deformities. Oper Tech Otolaryngol Head Nech Surg, 1995; 6:265-273

19-Athanasios Skouras, Fygalia, Anna Asimakopoulou, George Skouras, Maroulia Divritsioti, Katerina Dimitriadi: Use of the Goldman Technique to Correct Both the Overprojected and the Broad Nasal Tip. Aesth Plast Surg, 2012; 36:54-61

20-Goldman IB: The importance of the medial crura in nasal Tip reconstruction. AMA Arch Otolaryngol, 1957; 65:143-147.

21-Nolst-Trenite' GJ: Surgery of the nasal tip: intranasal approach. In: Papel ID (ed) Facial plastic and reconstructive surgery. Thieme, Stuttgart, 2009; pp 563576

22-Rui Xavier: Nasal Tip Plasty: The Delivery Approach Revisited. Aesth Plast Surg , 2013; 37:16-21

23-Holger G. Gassner: Structural grafts and suture techniques in functional and aesthetic rhinoplasty. GMS Current Topics in Otorhinolaryngology - Head and Neck Surgery 2010; 9: 1865-1011. 